\title{
TESTS OF ARRANGEMENTS IN A PROTOTYPE OF A STEAM GENERATOR IN AN ABSORPTION REFRIGERATION SYSTEM
}

\author{
R. F. M. Santos ${ }^{\mathrm{a}}$ \\ K. L. Cezar ${ }^{b}$, \\ P. A. C. Rocha ${ }^{a}$, \\ R. J. P. Lima ${ }^{a}$, \\ M. E. V. da Silva ${ }^{a}$, \\ and S. C. S. Alcântara ${ }^{c}$ \\ ${ }^{a}$ Universidade Federal do Ceará \\ Departamento de Engenharia Mecânica \\ Laboratório de Energia Solar e Gás Natural \\ Bairro Pici \\ CEP. 60020-181, Fortaleza, Ceará, Brasil \\ rogenheiro99@gmail.com \\ paulo.rocha@ufc.br \\ rjponteslima@gmail.com \\ eugenia@ufc.br \\ ${ }^{\text {b} U n i v e r s i d a d e ~ F e d e r a l ~ d o ~ P i a u i ́ ~}$ \\ Departmento de Engenharia Mecânica \\ Centro de Tecnologia \\ Bairro Ininga \\ CP. 64049-550, Teresina, Piauí, Brasil \\ kleberneue3@gmail.com \\ ${ }^{\mathrm{c}}$ Universidade Federal do Pernambuco \\ Departamento de Engenharia Mecânica \\ Bairro Várzea \\ CP. 50740-530, Recife, Pernambuco, Brasil \\ s.alcaantara@gmail.com \\ Received: October 19, 2018 \\ Revised: November 20, 2018 \\ Accepted: April 22, 2019 \\ ABSTRACT \\ This paper presents a proposal to optimize the prototype II of a steam \\ generator, developed by the Cooperativa de Pesquisa Norte/Nordeste de Gas \\ Natural, RECOGÁS - UFPB, which is a component of an absorption \\ refrigeration system of water and lithium bromide triggered by direct \\ burning of natural gas. The optimization was carried out through changes in \\ the arrangement, geometry, and number of the heat exchanger pipes. It was \\ developed a computational code using F-Chart software Engineering \\ Equation Solver ${ }^{\circledR}$ (EES), applying the principles of heat transfer to all the \\ different geometries. As a result, their respective coefficients of heat \\ transfer, heat flow rate and other parameters of the process were obtained. \\ The findings are organized in a table and represented in graphs generated by \\ the EES software, allowing to verify which factors had a greater influence \\ on the process, as well as the most efficient geometries. Internal convection \\ was identified as the governing factor in the heat transfer process. Some of \\ the geometries presented satisfactory values to the product of overall heat \\ transfer coefficient and surface area (UA) and also to the heat transfer rate \\ in the steam generator. Other ones presented a better thermal efficiency \\ relation with the amount of volume occupied in the steam generator. Some \\ geometries did not present satisfactory values under any aspect. \\ Keywords: optimization; steam generator; heat transfer; refrigeration

\section{NOMENCLATURE} \\ A cross-sectional area, $\mathrm{m}^{2}$ \\ a larger radius of the ellipse, $\mathrm{m}$ \\ b minor radius of the ellipse, $m$ \\ $\mathrm{C}_{\mathrm{p}} \quad$ specific heat, $\mathrm{kJ} / \mathrm{kg} . \mathrm{K}$ \\ D diameter, $\mathrm{m}$ \\ f friction factor \\ g gravity, $\mathrm{m} / \mathrm{s}^{2}$ \\ h convection coefficient, $\mathrm{W} / \mathrm{m}^{2} . \mathrm{K}$ \\ $\mathrm{h}_{\mathrm{lv}} \quad$ enthalpy of phase change, $\mathrm{kJ} / \mathrm{kg}$ \\ $\mathrm{k} \quad$ thermal conductivity, $\mathrm{W} / \mathrm{m} . \mathrm{K}$ \\ L length, $\mathrm{m}$ \\ m mass flow rate, $\mathrm{kg} / \mathrm{s}$ \\ $\mathrm{Nu} \quad$ Nusselt number \\ $\mathrm{P} \quad$ pressure, $\mathrm{kPa}$ \\ $\mathrm{p} \quad$ perimeter, $\mathrm{m}$ \\ Pr Prandtl number \\ Q overall heat transfer rate, $\mathrm{kW}$ \\ Re Reynolds number \\ $\mathrm{R}_{\mathrm{f}} \quad$ fouling factor, $\mathrm{m}^{2} . \mathrm{K} / \mathrm{W}$ \\ $\mathrm{T}$ temperature, $\mathrm{K}$ \\ $\mathrm{U} \quad$ overall heat transfer coefficient, $\mathrm{W} / \mathrm{m}^{2} . \mathrm{K}$ \\ UA product of overall heat transfer coefficient
}


and surface area, $\mathrm{W} / \mathrm{K}$

$x$ concentration

\section{Greek symbols}

$\begin{array}{ll}\Delta & \text { variation } \\ \eta & \text { efficiency } \\ \rho & \text { density, } \mathrm{kg} / \mathrm{m}^{3} \\ v & \text { kinematic viscosity, } \mathrm{m}^{2} / \mathrm{s}\end{array}$

\section{Subscripts}

\begin{tabular}{|c|c|}
\hline air & air properties \\
\hline cond & conduction \\
\hline conv & convection \\
\hline e & evaporator \\
\hline ext & external \\
\hline g & steam generator \\
\hline $\mathrm{h}$ & hydraulic \\
\hline int & internal \\
\hline in & inlet \\
\hline $\mathrm{ml}$ & $\log$ mean \\
\hline out & outlet \\
\hline $\mathrm{p}$ & profile \\
\hline s & surface \\
\hline sol & solution \\
\hline steel & steel properties \\
\hline $\mathrm{t}$ & total \\
\hline $\mathrm{V}$ & vapor \\
\hline vol & volumetric \\
\hline$\infty$ & free stream \\
\hline 3 & heat exchanger outlet/steam generator inlet \\
\hline 4 & steam generator inlet/heat exchanger outlet \\
\hline 7 & steam generator outlet /condenser inlet \\
\hline 20 & exhaust gas inlet in the steam generator \\
\hline 21 & exhaust gas outlet in the steam generator \\
\hline
\end{tabular}

\section{INTRODUCTION}

Energy plays an important role in raising the modern economy to industry, agriculture, transport and domestic uses in any nation. Power plants burning fossil fuels contribute to $80 \%$ of the world's energy generation (Kumar, 2017). However, several problems such as environmental pollution, increased costs in production and distribution, and inefficacious operations can be attributed to the high dependence of this energy source (Kayabasi and Kurt, 2018). This is one reason why developing countries are struggling to fill the energy gap between demand and supply by the applications of new energy resources (Agarwal and Sarviya, 2016).

Policies to stimulate renewable sources applications, which are originated from natural resources that have a regenerative capacity, have provided a range of opportunities. These resources include: solar energy, wind energy, biomass, as well as the use of cleaner sources such as biogas and natural gas that diminishes the environmental damage by lower carbon dioxide emissions than coal. These applications range from the use of heat obtained from solar collectors, gases exhausted from internal combustion engines and turbines, until absorption cooling units triggered by direct burning gas (Santos, 2017).

Thermal systems are always a topic of study and discussion in engineering. The interest in such subject is focused on the complexity in describing all the phenomena involved in the heat exchange or, simply, on the inherent fluid dynamics problems (Galarça et al., 2014). However, there is a constant search for the optimization of processes and devices involved in absorption refrigeration systems, due to the increase in its demands, mainly for industrial refrigeration purposes. In this way, it is essential to implement heat exchangers with lower volumes, maintaining or even improving its heat transfer rate per unit volume occupied (Incropera and Dewitt, 2008). Under such a framework, this paper presents the optimization of a steam generator using a direct burning gas to trigger a cooling unit by absorption of lithium bromide solution.

\section{METHODOLOGY}

Figure 1 illustrates a process flowchart of the absorption refrigeration system with lithium bromidewater solution. It is aimed, in this work, to analyze and test different geometries and a varied number of pipes of steam generator, as a means to perform the system optimization. In order to carry out the modeling of the heat transfer in the steam generator, the thermodynamic properties of the involved process fluids, and the geometric characteristics of the refrigeration unit analyzed are taken into account.

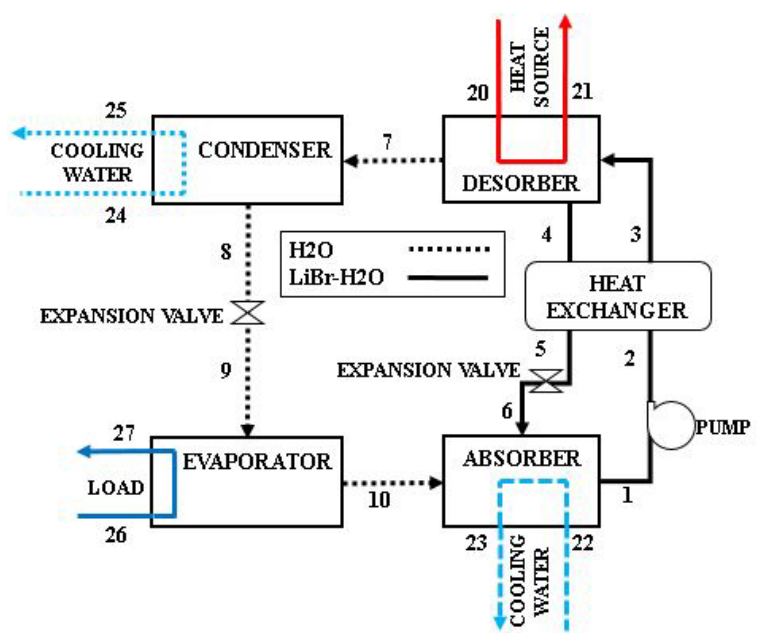

Figure 1. Single effect $\mathrm{LiBr}-\mathrm{H}_{2} \mathrm{O}$ absorption refrigeration system.

\section{Steam Generator}

The steam generator structure is completely built in stainless steel, and it has a heat exchanger inside, whose purpose is to take advantage of the heat 
from the exhaust gases to concentrate the absorbent solution of lithium bromide by evaporating its water. The study of the steam generator was performed based on the control volume shown in Fig. 2, and the heat transfer analysis adopted the following simplifying hypotheses:

- $\quad$ The heat loss to the neighbors is negligible;

- $\quad$ The flow of the fluids occurs in a steady state and fully developed regime;

- The variations of kinetic and potential energy are not considerate;

- The pipe wall thickness measures one millimeter for all geometries.

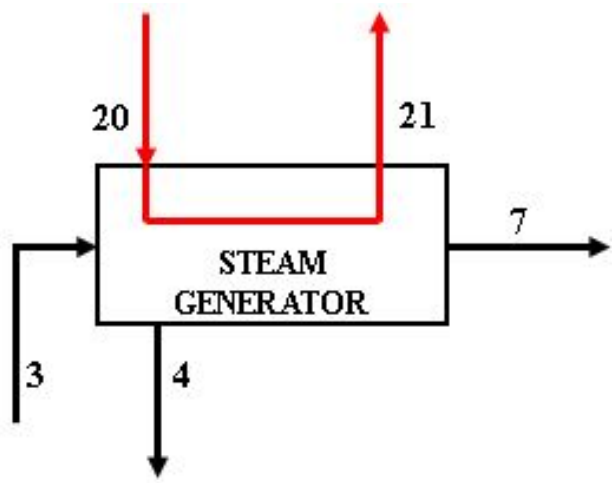

Figure 2. Control volume for the Steam Generator.

The steam generator analysis assesses a computational model in which the input parameters comes from the study published by Souza et al. (2010) and are presented in tab. 1.

Table 1. Input parameters for the computational model.

\begin{tabular}{|c|c|c|c|c|}
\hline Points & $\mathrm{P}(\mathrm{kPa})$ & $\mathrm{T}(\mathrm{K})$ & $\dot{\mathrm{m}}(\mathrm{kg} / \mathrm{s})$ & $\mathrm{x}(\%)$ \\
\hline 3 & 6.275 & 336.75 & 0.054730 & 54.9 \\
\hline 4 & 6.275 & 364.28 & 0.046950 & 64.0 \\
\hline 7 & 6.275 & 353.74 & 0.007782 & - \\
\hline 20 & 101.3 & 573.15 & 0.214300 & - \\
\hline 21 & 101.3 & 473.15 & 0.214300 & - \\
\hline
\end{tabular}

The heat transfer processes were parametrized for all proposed geometries of the steam generator using a computational code developed applying the EES software demo. This code contains the equations for the calculations of Reynolds, Prandtl and Nusselt numbers, hydraulic pipe diameter, friction factor, internal and external convection coefficients, overall heat transfer coefficient, heat transfer rate and thermal efficiency. All equations are taken from the literature.

\section{Internal Flow}

In order to determine the flue gas properties, its operating temperature was adopted as the arithmetic mean of the inlet and outlet temperatures in the steam generator, referring to points 20 and 21, respectively, in table 1 and figure 2 . In addition, due to difficulties in assessing the exhaust gases properties, it is admitted the hypothesis of the gases functioning as atmospheric standard air. As the operating temperature of the steam generator does not exceed $973.15 \mathrm{~K}$ and, consequently, no reaction occurs between the nitrogen and the oxygen to form NOx compounds, there is therefore evidence to support this hypothesis.

Reynolds and Nusselt numbers, as well as the friction factor for flow into non-circular tubes are based on the hydraulic diameter, which is defined as:

$$
\mathrm{D}_{\mathrm{h}}=\frac{4 \mathrm{~A}_{\mathrm{p}}}{\mathrm{p}}
$$

According to Mattiusi et al. (2007) the hydraulic diameter for elliptic profile tubes is calculated by the following equation:

$$
D_{h}=\frac{4 a b}{\sqrt{2\left(a^{2}+b^{2}\right)}}
$$

Considering the internal surface of the tubes as being smooth, the friction factor in turbulent flow can be determined from the first explicit equation of Pethukov (1970), which is given as:

$$
f=(0.79 \ln \operatorname{Re}-1.64)^{-2}
$$

According to Çengel and Ghajar (2011), the relations most used to estimate the Nusselt number can generate errors of up to $25 \%$. In order to reduce this miscalculation to less than $10 \%$ and obtain more accurate results, it was chosen to apply the equation of Gnielinski (1976), which is given by:

$$
\mathrm{Nu}=\frac{\left(\frac{\mathrm{f}}{8}\right) \cdot(\mathrm{Re}-1000) \cdot \operatorname{Pr}}{1+12.7 \cdot\left(\frac{\mathrm{f}}{8}\right)^{0.5}\left(\operatorname{Pr}^{\left(\frac{2}{3}\right)}-1\right)}
$$

Where $\mathrm{Re}$ is the Reynolds number, $\operatorname{Pr}$ is the Prandtl number and $\mathrm{f}$ the friction factor.

Using the Nusselt number value estimated in equation 4, it becomes possible to calculate the internal convection coefficient by the following equation:

$$
\mathrm{h}_{\mathrm{int}}=\frac{\mathrm{Nu} \cdot \mathrm{k}_{\mathrm{air}}}{\mathrm{D}_{\mathrm{int}}}
$$

Where $\mathrm{k}_{\mathrm{air}}$ is the thermal conductivity coefficient of air and $D_{\text {int }}$ is the internal pipe diameter.

\section{External Flow}


Following the flowchart shown in figure 2, the steam generator receives an aqueous solution of medium concentration lithium bromide (3) which, upon exchanging heat with the steam generator tubes (20-21), separates into two outlet streams: water vapor to the condenser, and lithium bromide solution in high concentration to the absorber. That means in this way there are two exits, in such way that the outlet 4 directs to the condenser and outlet 7 to the absorber.

According to Rocha (2010), in order to facilitate the calculations, it is necessary to work only with one input and one output, thus some procedures were followed to determine a weighted average temperature for the water vapor output and the concentrated lithium bromide solution, considering it to be a single outlet.

$$
\mathrm{T}_{\mathrm{sol}}=\frac{\mathrm{T}_{4} \dot{\mathrm{m}}_{4}+\mathrm{T}_{7} \dot{\mathrm{m}}_{7}}{\dot{\mathrm{m}}_{3}}
$$

The temperature of the solution is given by equation 6 . The subscript numbers in the equation refer the points of the control volume depicted in Fig. 2 and listed in Tab. 1.

Thus, the temperature located at a point distant from the surface of the pipes is determined, i.e., the free-stream temperature, given by:

$$
\mathrm{T}_{\infty}=\frac{\mathrm{T}_{\mathrm{sol}}+\mathrm{T}_{3}}{2}
$$

The surface temperature of the steam generator pipes was considered as an arithmetic mean between the inlet and outlet temperatures of the flue gases, given by:

$$
\mathrm{T}_{\mathrm{s}}=\frac{\mathrm{T}_{20}+\mathrm{T}_{21}}{2}
$$

According to Souza et al. (2010), all these parameters must be determined because, with them, it is then possible to identify the boiling regime of the water, allowing to take better advantage of its heat of absorption. In addition, the difference between the temperature of the tube surface and the water saturation temperature, which in this case is identified as the free-stream temperature, should always be determined. The latter refers to water in the saturated vapor state, in addition to the Leidenfrost Point, in this interval, the film boiling is configured. The EES software provided the properties of the solution and the vapor.

$$
\mathrm{h}_{\text {ext }}=\frac{\mathrm{k}_{\text {steel }}}{\mathrm{D}_{\text {ext }}} \cdot 0.62 \cdot\left[\frac{\mathrm{g} \cdot\left(\rho-\rho_{\mathrm{v}}\right) \cdot \mathrm{h}_{\mathrm{lv}} \cdot \mathrm{D}_{\text {ext }}^{3}}{\mathrm{v}_{\mathrm{v}} \cdot \mathrm{k}_{\text {steel }} \cdot\left(\mathrm{T}_{\mathrm{s}}-\mathrm{T}_{\infty}\right)}\right]^{\frac{1}{4}}
$$

Equation (9) can be applied to calculate the external convection coefficient in the film boiling process for horizontally arranged cylinders (Souza et al., 2010). In this, $\mathrm{k}_{\text {steel }}$ is the thermal conductivity coefficient of steel, $\mathrm{D}_{\text {ext }}$ is the external diameter of the pipe, $g$ is the acceleration of gravity. The specific mass of the solution is given by $\rho$, where $\rho_{\mathrm{v}}$ is the density of the water vapor, $h_{l_{v}}$ is the enthalpy of phase change and $v_{v}$ is the kinematic viscosity of the water vapor.

\section{Overall heat transfer coefficient, heat transfer rate and efficiencies}

For the calculation of the global coefficient of heat transfer, the following equation was used:

$$
\mathrm{U}=\left(\frac{1}{\mathrm{~h}_{\text {int }} \cdot \mathrm{A}_{\text {in }}}+\frac{\mathrm{R}_{\mathrm{f}}}{\mathrm{A}_{\text {in }}}+\frac{\ln \left(\frac{\mathrm{D}_{\text {ext }}}{\mathrm{D}_{\text {int }}}\right)}{2 \cdot \pi \cdot \mathrm{k}_{\text {steel } \mathrm{L}}}+\frac{1}{\mathrm{~h}_{\text {ext }} \cdot \mathrm{A}_{\text {out }}}\right)^{-1}
$$

The fouling resistance factor $R_{f}$ was considered for the internal surface due to particle depositions inside the tubes when flue gases pass by them. $A_{\text {in }}$ and $A_{\text {out }}$ are the inner and outer areas of the pipes and $L$ corresponds to its length.

In theory, before having any idea about the heat exchanger itself, the heat transfer rate provided during the process is given by the following equation:

$$
\dot{\mathrm{Q}}=\dot{\mathrm{m}} \cdot \mathrm{c}_{\mathrm{p}} \cdot \Delta \mathrm{T}
$$

Where $c_{p}$ is the specific heat of the thermal fluid and $\Delta \mathrm{T}$ is the difference between the inlet and outlet temperatures of the fluid. However, it is known that thermal losses occur during the heat transfer process, either due to physical limitations or material properties of the steam generator. Therefore, in the analysis of heat exchangers, the heat transfer rate is determined by the following equation:

$$
\dot{\mathrm{Q}}_{\mathrm{g}}=\mathrm{UA}_{\mathrm{t}} \cdot \Delta \mathrm{T}_{\mathrm{ml}}
$$

Where $A_{t}$ is the sum of the internal and external areas of the pipes and $\Delta \mathrm{T}_{\mathrm{ml}}$ is the logarithmic mean temperature difference. To perform a more in-depth analysis of the steam generator efficiency, it is essential to calculate the yields of each geometry analyzed in this work. Thus, the steam generator efficiency was divided into thermal and volume efficiency (volume occupied by the pipes internally), and determined by the following equations:

$$
\eta_{\mathrm{g}}=\frac{\dot{\mathrm{Q}}_{\mathrm{g}}}{\dot{\mathrm{Q}}}
$$




$$
\eta_{\mathrm{vol}}=1-\frac{\text { Volume occupied by the pipes }}{\text { Internal volume of the steam generator }}
$$

\section{RESULTS AND DISCUSSION}

Five geometries, numbered as 01, 02, 03, 04 and 05 , are represented in figures 3,4 and 5 . The first geometry corresponds to the prototype (01) for which were proposed the new arrangements 02, 03, 04 and 05 . The original geometry consists of eight pipes with a rectangular profile organized in two semicircular arrangements.

For the first modification, presented in geometry 02, the semicircular conduits were maintained but using a round profile and, in this case, the efficiency of the steam generator was studied by reducing the number of ducts to four tubes. The volume occupied inside the steam generator was reduced, but at the same time increased the area of heat exchange in the pipes.

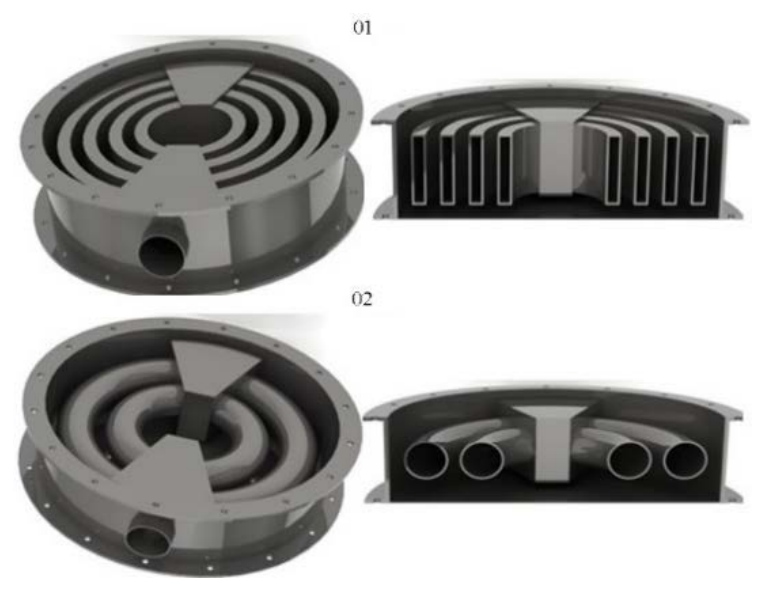

Figure 3. Top view and cross-section of the geometries.

Figure 4 shows the third and fourth proposed geometries. In the third model, similar to the prototype, the steam generator is internally composed by ducts with rectangular profile. However, there are only 4 tubes organized in a single row. This geometry and shape of the arrangement were chosen in order to obtain a larger area of heat exchange.

The elliptical profile was chosen to compose the equivalent steam generator in the fourth geometry, designed to arrange 14 tubes side by side in two parallel rows. This geometry was chosen to analyze the performance of the heat exchanger by increasing the number of tubes but reducing the volume occupied inside the shell. An elliptic contour makes it possible to vary the ratio between the major and minor axes of the pipes without compromising the hydraulic diameter.

The fifth and last configuration is designed to have 21 pipes of circular profile, disposed into three identical parallel lines. This geometrical configuration aims to analyze the influence of the increase in the number of tubes on the heat exchange processes compared to the other geometries studied, and considering the extended volume occupied inside the shell. This last geometry can be seen in Fig. 5 .
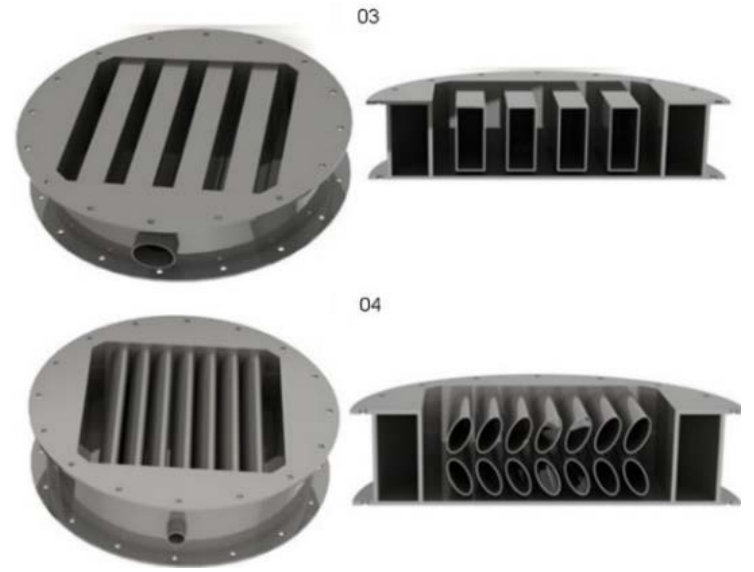

Figure 4. Top view and cross-section of the geometries.

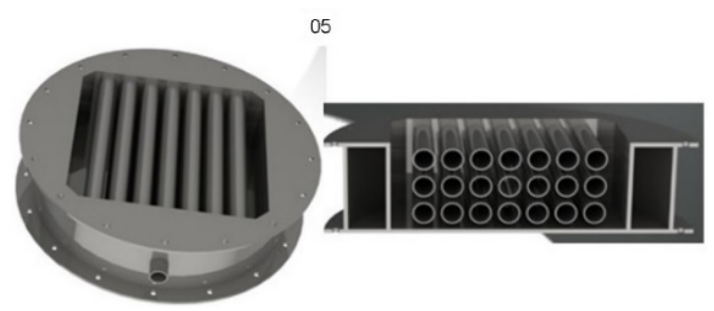

Figure 5. Top view and geometry cross-section.

Table 2 shows the geometric parameter values for each arrangement, such as the number of tubes and the hydraulic diameter. In addition, it presents the findings referring to the main parameters related to the heat transfer process.

It is possible to note that the values related to the

\begin{tabular}{|c|c|c|c|c|c|c|c|c|c|}
\hline Geometry & $\begin{array}{c}\mathrm{N}^{\mathrm{o}} \\
\text { pipes }\end{array}$ & $\begin{array}{c}\mathrm{D}_{\mathrm{h}} \\
(\mathrm{m})\end{array}$ & $\mathrm{Re}$ & $\begin{array}{c}\mathrm{h}_{\text {ext }} \\
\left(\mathrm{W} / \mathrm{m}^{2} \mathrm{~K}\right)\end{array}$ & $\begin{array}{c}\mathrm{h}_{\text {int }} \\
\left(\mathrm{W} / \mathrm{m}^{2} \mathrm{~K}\right)\end{array}$ & $\begin{array}{c}\mathrm{UA} \\
(\mathrm{W} / \mathrm{K})\end{array}$ & $\begin{array}{c}\mathrm{Q}_{\mathrm{g}} \\
(\mathrm{kW})\end{array}$ & $\begin{array}{c}\eta_{\mathrm{g}} \\
\%\end{array}$ & $\begin{array}{c}\eta_{\text {vol }} \\
\%\end{array}$ \\
\hline 01 & 8 & 0.02867 & 43112 & 28131 & 132.5 & 92.96 & 15.92 & 66.97 & 63.50 \\
\hline 02 & 4 & 0.08558 & 29224 & 20433 & 33.27 & 9.606 & 1.65 & 6.92 & 73.75 \\
\hline 03 & 4 & 0.06345 & 38955 & 22446 & 55.35 & 27.24 & 4.67 & 19.63 & 52.18 \\
\hline 04 & 14 & 0.03095 & 22818 & 27368 & 75.14 & 55.48 & 9.50 & 39.97 & 79.50 \\
\hline
\end{tabular}


\begin{tabular}{|c|c|c|c|c|}
\hline 05 & 21 & 0.03401 & 13847 & 26574 \\
\hline
\end{tabular} conduction process as well as the scale resistance factor are not included in Tab. 2. This is explained by the fact that these two parameters have little contribution to the final value of the heat rate supplied to the geometries of the steam generator.

The poor contribution of the heat conduction process on the heat flow can be well explained by the very thin wall thickness of the pipes. Çengel and Ghajar (2011) explain that the thermal resistance is negligible for thin wall pipes made of a material with high thermal conductivity, as is the case with the models in this work.

Regarding the incrustation thermal resistance, its low influence on the heat generation process can be explained by the high flow velocity of the combustion gases inside the pipes. One could also mention the fact that these gases are not at a high temperature. The sum of these factors contributes, therefore, to a low factor of incrustation, since this depends directly on the temperature of operation and the speed of the fluids.

As can be seen in Fig. 6, the external convection coefficient exerts a practically null influence on the value of the product UA and, consequently, on the heat rate supplied to the steam generator. This is evidenced by the constant behavior in the UA values for the different geometries, even with the external convection coefficient varying in large scale.

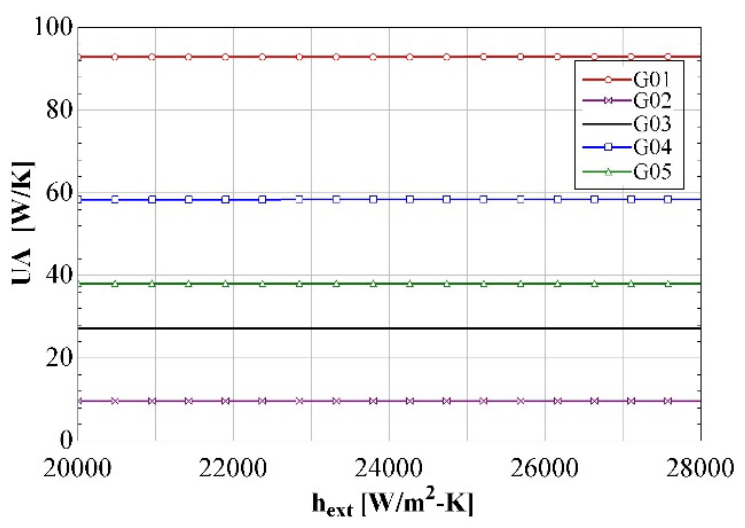

Figure 6. Product UA x External convection coefficient.

The internal convection coefficient is the determining factor for the value of the UA product, as seen in the graph (Fig. 7). These results agree with the statement by Çengel and Ghajar (2011), which explains that the heat transfer global coefficient is dominated by the smallest convection coefficient since the inverse of a large number is small. When one of the coefficients is much smaller than the other, as is the case of this study, where $\mathrm{h}_{\text {int }}<<\mathrm{h}_{\text {ext }}$, consequently $1 / h_{\text {int }}>1 / h_{\text {ext }}$, thus the overall heat transfer coefficient is practically equal to the smaller convection coefficient ( $\mathrm{U} \approx \mathrm{h}_{\text {int }}$ ). This situation occurs frequently when one of the fluids is a gas and the other is a liquid, which fits perfectly in the experiment treated in this paper.

According to Çengel and Ghajar (2011), this problem can be solved through the use of fins on the gas side to increase the UA product and consequently the heat transfer. However, the insertion of fins on the inner surface of the tubes becomes impracticable due to the dimensional limits of the steam generator, since, as can be seen in Tab. 2, all the pipes have small diameters. Therefore, the insertion of fins would be detrimental because, instead of promoting an increase in the heat transfer process, it could create an obstruction inside the pipes, making it difficult to pass the fluid compromising the performance of the steam generator.

Another reason to the non-use of fins concerns the increase in the price of the pipes, making the prototype of the steam generator more expensive and possibly impracticable from a commercial point of view.

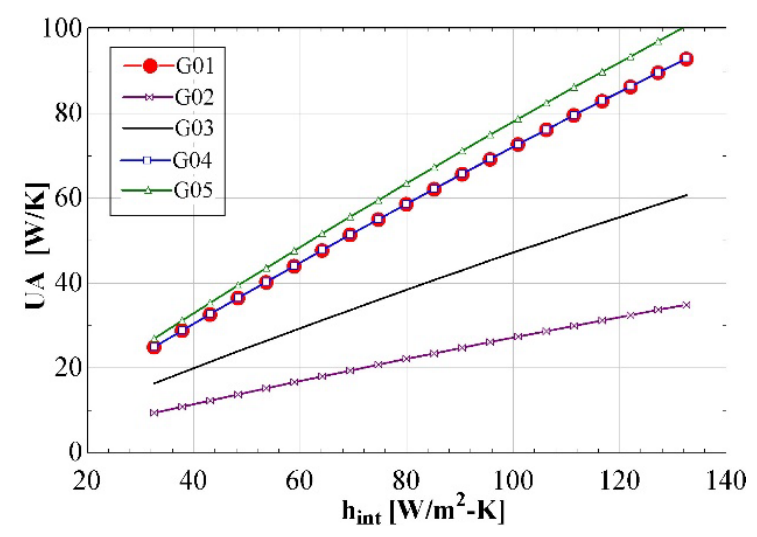

Figure 7. Product UA x Internal convection coefficient.

Figures 6 (straight lines) and 7 (ascending lines) indicate hypothetical curves of the UA product as a function of external and internal convection coefficients, respectively, for each analyzed geometry. In fact, each one has a single value, however, these simulations contribute to determine which convection coefficient had the greatest influence on the heat transfer process.

Figure 8 shows comparative values referring to thermal and volumetric efficiencies of the steam generator. The geometries 03 and 05 are less effective both from the point of view of steam generation and the volume occupied within the steam generator, and the geometry 02 in spite of the low volume occupied, it seems to be ineffective. One of the reasons for this assertion is based on the low thermal efficiency of such geometries, that is, on their low steam generation capacity, as can be assessed from the values presented in Table 2, for which the geometry 02 present the lowest values. Other 
probable reason is the large volume occupied by the geometries 03 and 05 . Large volumes taken by geometries become a problem because it restricts the space to the fluid flow. From the moment the solution of water-lithium bromide turns into steam and the vapor occupies an amount in volume of steam generator, it needs more space to run off to other stages of the cooling process. In addition, the liquid phase occupies a certain place in the steam generator, which corroborates to the decrease in the free volume for the vapor phase. Accordingly, the geometries 03 and 05 seem not to have enough volume to allow effective treatment.

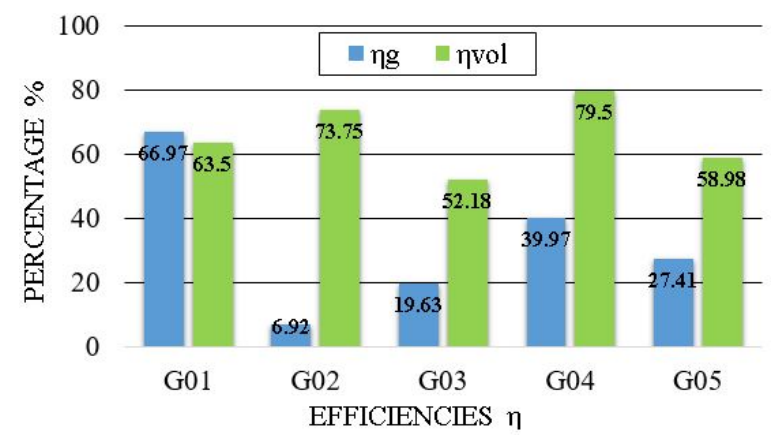

Figure 8. Thermal Efficiency x Volumetric Efficiency.

On the other hand, the geometries 01 and 04 present the best relations between thermal efficiency and volumetric efficiency. However, comparing only the new proposed geometries (i.e., 02, 03,04 and 05) the geometry 04 presents the most balanced relationship between thermal and volumetric efficiencies. Its thermal yield is approximately $60 \%$ of the thermal yield of geometry 01 , and its volumetric efficiency is approximately $25 \%$ higher. Considering what has already been mentioned in relation to the large space required by the steam and the solution inside the steam generator, the findings indicate that under this aspect the geometry 04 would be the most adequate.

On returning to Tab.2 it is possible to notice that the highest values of the UA product are found for the profiles of smaller diameter, contrasting with the smallest values of UA for the profiles with larger diameters. In theory, reducing the diameter of the profiles and increasing the number of tubes would give higher heat rates to the steam generator. Nevertheless, the geometries of the analyzed steam generator are clearly limited, since the diameters are already quite small and, therefore, the reduction of the diameters would entail in obstruction for the passage of combustion gases inside the tubes. Furthermore, such rearrangements would cause reductions on the Reynolds number and this would cause a modification in the flow regime of the hot fluid, changing from turbulent to laminar thereby completely altering characteristics and values relative to heat transfer.

\section{CONCLUSION}

This paper aimed to identify the best geometrical configuration for a steam generator of an absorption refrigeration system using the lithium bromide-water pair, with the specified dimensions, thus establishing the profile and the most suitable arrangements to carry out the heat exchange between the water-lithium bromide solution and exhaust gases from the direct burning of natural gas.

It was found that, depending on the parameter analyzed, a geometry stood out from the others. In terms of the UA product and the steam generation rate, the best configuration would be the former geometry 01 . On the other hand, taking into account the relationship between the smallest volume occupied inside the steam generator and the thermal efficiency, the proposed new geometry 04 provides a better yield than the other geometries. Finally, by performing an analysis without considering space limitations, and being completely free to increase the size of the steam generator, the geometry 05 would present the best performance, theoretically.

Regarding the purpose of this work, which was designed to optimize a prototype of a steam generator for an absorption refrigeration system, the objective has been achieved in some important aspects. The geometry 04 achieved a reasonable thermal yield occupying a much smaller volume than that of the initial prototype. Also, it was obtained another geometry (05) with better hypothetical values than the original design with respect to the global coefficient of heat transfer and that in situations where there are no space restrictions, it will provide a higher rate of heat to the steam generator.

As a suggestion for future work, the heat transfer analysis in the presented geometries can be done by changing the intermediate heat supply fluid to the steam generator for water heated by some external energy source, such as solar energy, direct burning of natural gas etc.

\section{ACKNOWLEDGMENTS}

The first author in this work thanks CNPq/CAPES for the financial support by means of the Master Degree scholarship.

\section{REFERENCES}

Agarwal, A., and Sarviya, R. M., 2016, An Experimental Investigation of Shell and Tube Latent Heat Storage for Solar Dryer Using Paraffin Wax as Heat Storage Material, Engineering Science and Technology, an International Journal, Vol. 19, pp. 619-631.

Çengel, Y. A., and Ghajar, A. J., 2011, Heat and Mass Transfer: Fundamentals \& Applications, 4th edition, The McGraw-Hill Companies. 
Galarça, M. M., Cardoso, F. R., A. L. Razera, A. L., Acunha Jr., I. C., Isoldi, L. A., Porte, A. F., Rocha, L. A. O., and Santos, E. D., 2015, Geometrical Optimization of a Triangular Arrangement of Cylinders Submitted to a Laminar Forced Convective Flow, Scientia Plena, Vol. 11, pp. 1-13.

Gnielinski, V., 1976, New Equations for Heat and Mass Transfer in Turbulent Pipe and Channel Flow, International Chemical Engineering, Vol. 16, pp. 359-368.

Incropera, F. P., and Dewitt, D. P., 2008, Fundamentos de Trasnferência de Calor e de Massa, $6^{\mathrm{a}}$ edição, LTC, Rio de Janeiro. (in Portuguese)

Kayabasi, E., and Kurt, H., 2018, Simulation of Heat Exchangers and Heat Exchanger Networks with an Economic Aspect, Engineering Science and Technolgy, an International Journal, Vol. 21, pp. 7076.

Kumar, R., 2017, A Critical Review on Energy, Exergy, Exergoeconomic and Economic (4-E) Analysis of Thermal Power Plants, Engineering Science and Technolgy, an International Journal, Vol. 20, pp. 283-292.

Mattiusi, E. M., Coradin, H. T., Brondani, W. M., Franco, A. T., Morales, R. E. M., and Martins, A. L., 2007, Escoamento Laminar de Fluidos NãoNewtonianos em Tubos de Seção Transversal Elíptica, in: Congresso Brasileiro de Pesquisa e. Desenvolvimento em Petróleo e Gás , $4^{\circ}$ PDPETRO, Campinas, São Paulo, pp. 1-8. (in Portuguese)

Petukhov, B. S., 1970, Heat Transfer and Friction in Turbulent Pipe Flow with Variables Physical Properties, In Advances in Heat Transfer, ed. T. F. Irvine and J. P. Harnett, Vol. 6, New York: Academic Press.

Rocha, M. A., 2010, Estudo TeóricoExperimental de um Sistema de Refrigeração por Absorção De Duplo-Efeito em Série Usando o par Água / Brometo de Lítio, Masters Thesis, UFPB, João Pessoa, PB. (in Portuguese)

Santos, P. H. D., 2005, Análise Energética e Exergética de Sistemas de Refrigeração por Absorção de Múltiplos Efeitos com o Par Brometo de Lítio Água, Masters Thesis, UFPB, João Pessoa, PB. (in Portuguese)

Santos, R. F. M., 2017, Otimização de um Gerador de Vapor para um Sistema de Refrigeração por Absorção Acionado por Gás Natural, Undergraduate Thesis, UFPI, Teresina, PI. (in Portuguese)

Souza, L. G., Souza, L. G. M., Moreira, H. L., and Santos, P. H. D., 2010, Development of a SingleEffect Absorption Refrigeration System Using Natural Gas and Solar Energy as the Source of Heat, in: 6th National Congress of Mechanical Engineering, CONEM, Campina Grande, Paraíba 